\title{
Astrocyte sodium signaling and neuro-metabolic coupling in the brain
}

\author{
Christine R. Rose* \& Jean-Yves Chatton ${ }^{\#}$ \\ *Institute of Neurobiology, Faculty of Mathematics and Natural Sciences, Heinrich-Heine- \\ University Düsseldorf, Universitätsstrasse 1, D-40225 Düsseldorf, Germany \\ \#Department of Fundamental Neurosciences, University of Lausanne, rue du Bugnon 9, CH- \\ 1005 Lausanne, Switzerland
}

*Corresponding author: Prof. Dr. Christine Rosemarie Rose, Institute of Neurobiology, Faculty of Mathematics and Natural Sciences, Heinrich Heine University Düsseldorf, Universitätsstrasse 1, D-40225 Düsseldorf, Germany. Phone: ++49 (211) 81 13416; Fax: ++49 (211) 81 13415; e-mail: rose@ uni-duesseldorf.de

Keywords: astrocytes, $\mathrm{Na}^{+} / \mathrm{K}^{+}$-ATPase, glutamate transport, neuron-glia interaction, metabolism 


\begin{abstract}
At tripartite synapses, astrocytes undergo calcium signaling in response to release of neurotransmitters and this calcium signaling has been proposed to play a critical role in neuron-glia interaction. Recent work has now firmly established that, in addition, neuronal activity also evokes sodium transients in astrocytes, which can be local or global depending on the number of activated synapses and the duration of activity. Furthermore, astrocyte sodium signals can be transmitted to adjacent cells through gap junctions and following release of gliotransmitters. A main pathway for activity-related sodium influx into astrocytes is via high-affinity sodium-dependent glutamate transporters. Astrocyte sodium signals differ in many respects from the well-described glial calcium signals both in terms of their temporal as well as spatial distribution. There are no known buffering systems for sodium ions, nor is there store-mediated release of sodium. Sodium signals thus seem to represent rather direct and unbiased indicators of the site and strength of neuronal inputs. As such they have an immediate influence on the activity of sodium-dependent transporters which may even reverse in response to sodium signaling, as has been shown for GABA transporters for example. Furthermore, recovery from sodium transients through $\mathrm{Na}^{+} / \mathrm{K}^{+}$-ATPase requires a measurable amount of ATP, resulting in an activation of glial metabolism. In this review, we present basic principles of sodium regulation and the current state of knowledge concerning the occurrence and properties of activity-related sodium transients in astrocytes. We then discuss different aspects of the relationship between sodium changes in astrocytes and neuro-metabolic coupling, putting forward the idea that indeed sodium might serve as a new type of intracellular ion signal playing an important role in neuron-glia interaction and neurometabolic coupling in the healthy and diseased brain.
\end{abstract}




\section{Introduction}

Active neurons and glial cells dynamically interact in many ways. One of the most prominent and most widely known examples of such an interaction was described about 30 years ago, through studies demonstrating that transmitters released by active neurons result in the activation of transmitter receptors on astrocytes (Bowman and Kimelberg, 1984, Kettenmann et al., 1984). It took about another 10 years before the advent of imaging techniques enabled the detection of astrocyte calcium signals in response to neuronal transmitters (Nedergaard, 1994). Astrocyte calcium signaling has since taken center stage in research efforts and interests. This is mainly because such signaling can result in the release of gliotransmitters and vasoactive substances by astrocytes, which thereby feedback onto and modulate the neuronal network (see chapters by Panatier/Robitaille and Volterra; this issue).

In addition to calcium signals, neuronal activity is, however, accompanied by a second type of ion signal in astrocytes: these are sodium transients, detected upon neuronal release of glutamate and -to a lesser extent- GABA. The existence of such activity-dependent sodium signals is surprising at first glance (Rose and Karus, 2013). First of all, they occur against a relatively high background sodium concentration $(10-15 \mathrm{mM})$, which is fundamentally different from other ion species involved in signaling (e. g. baseline intracellular calcium or proton concentrations are roughly around $100 \mathrm{nM}$ ). Also, as compared to calcium changes, which usually occur in the low $\mu \mathrm{M}$ range, sodium changes are a thousand-fold larger, occurring in the mM range. Furthermore, sodium signals not only differ in their magnitude, but also in their spatial and temporal profiles from classical calcium signaling in astrocytes. Sodium changes are quite long lasting, exhibiting decay times in the range of tens of seconds. Given the high diffusion coefficient for sodium ions measured in mammalian cytosol (0.6 $\mu \mathrm{m}^{2} / \mathrm{sec}$; (Kushmerick and Podolsky, 1969), sodium transients should, however, dissipate within fractions of a second. Apparently, free diffusion of sodium ions is considerably slowed because of increased tortuosity in the cytosol (Sykova and Nicholson, 2008), and/or binding to plasma membrane transporters such as the $\mathrm{Na}^{+} / \mathrm{K}^{+}$-ATPase. Moreover, a recent study has provided evidence for restricted molecular diffusion and the existence of subcellular compartments astrocytes (Nuriya and Yasui, 2013).

There are no known classical buffering mechanisms for sodium ions inside cells and, apart from the $\mathrm{Na}^{+} / \mathrm{K}^{+}$-ATPase (see below), there are no explicit sodium-binding proteins present that activate enzymes and enzyme cascades. Because sodium ions are central charge carriers, channel- or transporter-mediated influx of sodium resulting in changes in intracellular sodium concentration in the $\mathrm{mM}$ range, directly influences the cellular membrane 
potential. In contrast to the situation with calcium ions, there are no intracellular compartments or organelles which serve as storage compartments for sodium and thus there is no comparable release from stores.

When considering sodium signaling, it is also important to bear in mind that many secondary active transport systems depend on the sodium gradient and that sodium transients that is, a decrease in the inwardly directed sodium gradient- have an immediate impact on the driving force and activity of these transporters. Among those are transporters for regulation of other ions (e. g. sodium/proton exchange (NHE) and sodium/calcium exchange (NCX)) as well as transporters for the re-uptake of transmitters (e. g. high-affinity, sodium-dependent transporters for glutamate or GABA). In fact, it is conceptually astonishing how many highly relevant transporters work close to their equilibrium potential and may reverse upon increases in intracellular sodium. This topic has been comprehensively discussed recently and the reader is kindly referred to these earlier reviews (Kirischuk et al., 2012, Rose and Karus, 2013). One might argue that this is an inherent "weakness" of the system, based on a somewhat faulty design. Instead of this rather unsatisfactory argument, we prefer the interpretation that sodium transients might serve as signals.

A critical aspect in this argumentation is the question of what kind of information content such sodium signals might represent and encode. This point has not been fully been clarified yet and many questions still remain open. An established finding, however, is that extrusion of sodium ions is metabolically relevant because recovery from sodium signals requires a measurable amount of ATP. Thus, sodium increases will cause activation of glial metabolism. Consequently, activity-induced sodium transients are ideally positioned to take an essential signaling role in neuro-metabolic coupling between neurons and astrocytes.

\section{Sodium homeostasis and regulation}

Cellular sodium homeostasis is of the upmost functional importance for the brain and most of brain energy is in fact consumed by the $\mathrm{Na}^{+} / \mathrm{K}^{+}$-ATPases (Erecinska and Silver, 1994, Ames, 2000, Howarth et al., 2012). By transporting sodium ions out of the cell in exchange for potassium, the activity of the $\mathrm{Na}^{+} / \mathrm{K}^{+}$-ATPase establishes a low intracellular sodium concentration against a high sodium concentration in the extracellular space ( $\sim 145 \mathrm{mM}$; cf. Fig. 2; (Skou and Esmann, 1992, Kaplan, 2002, Somjen, 2004)). In hippocampal neurons, baseline sodium concentrations of about $12 \mathrm{mM}$ were reported, whereas data obtained from hippocampal astrocytes indicate a sodium concentration of about $11 \mathrm{mM}$ (e. g. (Rose and Ransom, 1996a, 1997b, Chatton et al., 2001, Sheldon et al., 2004, Langer and Rose, 2009). 
This indicates that, at least in this preparation, there is no significant difference in intracellular sodium concentrations between neurons and astrocytes. The cellular uptake of potassium by the $\mathrm{Na}^{+} / \mathrm{K}^{+}$-ATPase results in a high intracellular potassium concentration $(>100 \mathrm{mM})$ as compared to that of the extracellular space ( $2 \mathrm{mM}$; (Erecinska and Silver, 1994, Kofuji and Newman, 2004)). In light of the essential role of sodium homeostasis for cellular function, it is remarkable that the sodium pump is the only transport mechanism for efficient extrusion of sodium across the plasma membrane. Regulation of most other ions, in contrast, involves at least two mechanisms (e. g. plasma membrane $\mathrm{Ca}^{2+}$-ATPase works together with sodium/calcium-exchangers (NCX) to extrude calcium ions and several other transporters in addition to the $\mathrm{Na}^{+} / \mathrm{K}^{+}$-ATPase mediate uptake of potassium).

Low intracellular sodium concentrations together with the about 10-fold higher extracellular sodium concentration and negative cellular membrane potentials result in inwardly directed electro-chemical gradients for sodium ions across the plasma membrane of both neurons and glial cells. Thus, most of the basic currency of cellular metabolism, ATP, is converted into -and stored as- a strong inward driving force for sodium ions. This enables sodium-dependent electrical signaling and serves to energize many secondary transport processes across the plasma membrane (Rose and Karus, 2013). Changes in intracellular sodium will ultimately feed back on the activity of such sodium-dependent transport processes. Among these are transporters for the re-uptake of glutamate as well as of GABA and glycine, and the latter two may even reverse in response to sodium elevations (Kirischuk et al., 2012, Rose and Karus, 2013). There is also increasing evidence that sodium transients directly modulate intracellular calcium signaling through reversal of NCX (Kirischuk et al., 2012).

The transport cycle of the $\mathrm{Na}^{+} / \mathrm{K}^{+}$-ATPase has been characterized in great detail in cell culture models and heterologous expression systems, and new crystal structures of defined binding states are continuously being published (Morth et al., 2011, Kanai et al., 2013, Nyblom et al., 2013). Despite its central importance, the pump's functional properties in astrocytes and neurons in the intact brain, including basic attributes such as ion binding affinities or intracellular interaction partners, are poorly understood. One problem that arises in studies addressing these issues is that manipulation of sodium and the $\mathrm{Na}^{+} / \mathrm{K}^{+}$-ATPase in the intact tissue directly alters basic physiological cellular parameters and influences extracellular ion homeostasis. Moreover, "the sodium pump" is in fact a protein complex comprised of different subunits $(\alpha, \beta)$ of which different isoforms and binding partners $(\gamma /$ FXYD subunits) exist, and each of the possible combinations may result in different 
functional properties (Blanco and Mercer, 1998, Kaplan, 2002, Crambert and Geering, 2003). Furthermore, the $\mathrm{Na}^{+} / \mathrm{K}^{+}$-ATPase is subject to additional regulation and modulation by endogenous ouabain-like compounds binding to $\alpha 1$-subunits (Kala et al., 2000).

It is widely held that both neurons and astrocytes ubiquitously express a $\mathrm{Na}^{+} / \mathrm{K}^{+}$ATPase complex containing the $\alpha 1$-subunit and that the activity of this complex mediates "housekeeping" functions by setting the baseline sodium concentration and counteracting constitutive sodium influx. In addition to $\alpha 1$, neurons seem to preferentially express the $\alpha 3$ and astrocytes the $\alpha 2$ subunit, both of which have been suggested to handle sodium loads imposed during periods of high activity (Pellerin and Magistretti, 1997, Zahler et al., 1997, Azarias et al., 2013). Earlier studies also suggest that astrocytes are able to efficiently take up potassium from the extracellular space following activity, which is attributed to a higher $K_{d}$ for extracellular potassium in astrocytes compared to neurons (Kofuji and Newman, 2004, Hertz et al., 2013, Rose and Karus, 2013). While the functional relevance of this property was long acknowledged in the light of the necessity for extracellular potassium clearance only, recent work has established that activation of glial $\mathrm{Na}^{+} / \mathrm{K}^{+}$-ATPase by extracellular potassium is also involved in neuro-metabolic coupling and the stimulation of glycolysis by potassium (Bittner et al., 2011).

A third major difference in the mechanisms of sodium homeostasis and regulation between astrocytes and neurons arises from a fundamental difference in the intercellular coupling between these two cell types. In astrocytes, an additional pathway for the recovery from local sodium loads exists. This additional pathway is represented by gap junctions, which can mediate the rapid diffusion and distribution of sodium to neighboring cells (Rose and Ransom, 1997a, Langer et al., 2012).

\section{Dynamic changes in extra- and intracellular sodium during neural activity}

\section{1. Sodium signals in the extracellular space and in neurons}

Experiments with ion-selective microelectrodes performed in the vertebrate brain in vivo and in acute tissue slices, have demonstrated that activity-related opening of sodium-permeable voltage- or ligand-gated ion channels, and the flux of sodium through these channels, can alter the sodium concentration in the extracellular space. At the existing high extracellular baseline sodium concentration, the response characteristics of ion-selective microelectrodes are not 
favourable for the study of sodium signals evoked by minor or moderate levels of activity. With prolonged afferent stimulation or with induction of epileptiform discharges or spreading depression, however, this technique enabled detection of decreases in the extracellular sodium by up to about $15 \mathrm{mM}$ (Dietzel et al., 1982, Zanotto and Heinemann, 1983, Hablitz and Heinemann, 1989, Kohr and Heinemann, 1989); Fig. 1A).

Based on earlier studies in invertebrate preparations, it was long assumed that physiological activity is not accompanied by measurable changes in intracellular sodium concentrations (e. g. (Hodgkin and Huxley, 1952); many current text books). In intracellular compartments which have a high surface-to-volume ratio such as in vertebrate neurons and glial cells, the situation is quite different. Indeed, dynamic measurements using sodium-sensitive fluorescent dyes have now established that action potentials cause an increase in the sodium concentration in axons due to sodium influx through TTX-sensitive, voltage-gated channels (Lasser-Ross and Ross, 1992, Kole et al., 2008, Fleidervish et al., 2010, Baranauskas et al., 2013). In cortical pyramidal neurons, maximal amplitudes for sodium increases were obtained in the axon initial segment, and computer simulations indicated an increase by about $10 \mathrm{mM}$ with trains of 10-12 action potentials (Kole et al., 2008).

Activity-induced sodium transients can also arise in dendrites in response to the opening of voltage-gated sodium channels during back-propagating action potentials, as is the case in hippocampal and cortical neurons ((Jaffe et al., 1992, Rose et al., 1999, Lamy and Chatton, 2011); Fig. 1B; cf. Fig. 2). Action potential-induced sodium transients reached values of $4 \mathrm{mM}$ in apical dendrites of hippocampal neurons following a train of 20 action potentials and monotonically decayed with a time constant of several seconds (Rose et al., 1999). Particularly prominent postsynaptic sodium transients are seen with glutamatergic synaptic activity and opening of ionotropic glutamate receptors generating long-lasting, substantial currents across the membrane ((Callaway and Ross, 1997, Rose and Konnerth, 2001, Bennay et al., 2008, Langer and Rose, 2009); Fig. 1C; cf. Fig. 2). In apical dendrites of hippocampal CA1 pyramidal neurons, sodium increases rose by about $10 \mathrm{mM}$ were detected in response to short-burst stimulation (5 pulses at $50 \mathrm{~Hz}$ ) (Rose and Konnerth, 2001). In active spines, stimulus-induced sodium increases even reached to up $35-40 \mathrm{mM}$ following this stimulation paradigm (Rose and Konnerth, 2001). Such activity-induced influx of sodium into neurons through ionotropic glutamate receptors and voltage-gated channels in fact represents the main energy-consuming process in the brain and requires most of the ATP produced (Erecinska and Silver, 1994, Lennie, 2003, Harris et al., 2012). 


\section{2. Sodium signals in astrocytes}

The main mechanism for the inactivation of synaptically released glutamate is its fast binding to and cellular reuptake by high-affinity transporters (Danbolt, 2001, Tzingounis and Wadiche, 2007). In the rodent hippocampus, this task is mainly accomplished by astrocytic glutamate transporters (EAATs; excitatory amino acid transporters), namely GLAST (glutamate/aspartate-transporter) and GLT-1 (glutamate-transporter-1; rodent analogues of EAAT1 and EAAT2, respectively; (Gegelashvili and Schousboe, 1998, Bergles et al., 1999, Anderson and Swanson, 2000, Maragakis and Rothstein, 2004, Marcaggi and Attwell, 2004); Fig. 2). High-affinity glutamate uptake is energized by the concomitant inward transport of three sodium ions and a proton, while one potassium ion is transported outward. Consequently, its activation is accompanied by an inward current as well as intracellular acidification and an increase in the intracellular sodium concentration of astrocytes (Rose and Ransom, 1996b, Deitmer and Rose, 2010, Kirischuk et al., 2012).

This uptake mechanism was first demonstrated in cultured astrocytes, in which application of glutamate or its transportable agonist D-aspartate readily evoke substantial increases (> $10 \mathrm{mM}$ ) in intracellular sodium concentration (Kimelberg et al., 1989, Rose and Ransom, 1996b, Chatton et al., 2000, Chatton et al., 2001). These are suppressed by the glutamate uptake blocker TBOA (Chatton et al., 2001, Bernardinelli and Chatton, 2008) or its higher-affinity version TFB-TBOA (Tsukada et al., 2005, Bozzo and Chatton, 2010). Cytosolic sodium elevations induced by glutamate are accompanied by sodium signals in mitochondria as well, indicating a link between glutamate-evoked sodium signalling and mitochondrial function as discussed below (see chapter 4. 3., this article; (Bernardinelli et al., 2006)). Sodium-dependent glutamate uptake also represents a powerful pathway for the induction of astrocyte sodium signals in situ, including astrocytes in cerebellum (Kirischuk et al., 2007, Bennay et al., 2008), hippocampus (Langer and Rose, 2009), neocortex ((Lamy and Chatton, 2011, Unichenko et al., 2013); Fig. 1D), and at the Calyx of Held (Uwechue et al., 2012). Sodium typically increased by several $\mathrm{mM}$ in the cell bodies with exogenous application of glutamate or D-aspartate. GABA transporters provide another pathway for sodium influx into astrocytes. GABA uptake is, however, coupled to co-transport of two sodium ions only (Gadea and Lopez-Colome, 2001), and evokes significantly smaller sodium increases as compared to glutamate (Chatton et al., 2003, Unichenko et al., 2012). In cultured mouse cortical astrocytes for example, the maximum amplitude of sodium increases in response to $500 \mu \mathrm{M}$ GABA was 4-6 mM, compared with an increase by $25-30 \mathrm{mM}$ in response to an application of glutamate at comparable concentrations (Chatton et al., 2003). 
Astrocytes undergo sodium signaling with stimulation of excitatory synaptic activity and synaptic glutamate release. In acutely isolated tissue slices of the cerebellum, brief stimulation of parallel fibers caused sodium transients of up to $9 \mathrm{mM}$ in Bergmann glial cells ((Kirischuk et al., 2007, Bennay et al., 2008); Fig. 1E). Stimulation of climbing fibers, in contrast, induced global sodium signals in Bergmann glial cells, the amplitude and time course of which did not significantly differ between different branches and the soma (Bennay et al., 2008). Synaptically-induced sodium transients in the $\mathrm{mM}$ range were also detected in astrocytes of the CA1 stratum radiatum of the juvenile mouse hippocampus (Langer and Rose, 2009). With low stimulation intensities, hippocampal astrocytes displayed differences in amplitude and time course of activity-induced sodium signals between different cellular regions. Under these conditions, sodium signals amounted to $1-2 \mathrm{mM}$, were confined to one or two primary branches and adjacent fine processes and only weakly invaded the soma. Increasing the number of activated synapses by increasing the stimulation intensity increased the amplitude of sodium transients to up to $6.0 \mathrm{mM}$ and resulted in global sodium transients that included the soma (Langer and Rose, 2009). Sodium signals in astrocytes thus seem to represent indicators of the location and strength of synaptic activity.

Pharmacological approaches have indicated that the sodium influx pathways activated by synaptic stimulation differ between Bergmann glial cells and hippocampal astrocytes, although both express sodium-dependent glutamate transporters (Danbolt, 2001, Schousboe et al., 2004, Schreiner et al., 2014). The glutamate uptake blocker TBOA virtually eliminated sodium transients in hippocampal astrocytes, indicating that they were predominately mediated by this pathway (Langer and Rose, 2009). Further, application of D-aspartate, an agonist of glutamate transport, reliably induced sodium signals in processes of hippocampal astrocytes (Langer and Rose, 2009). In Bergmann glia, in contrast, synaptically-induced sodium signals were reduced by only $\sim 60 \%$ with TBOA. The remaining signal was blocked by blockade of AMPA receptors (Bennay et al., 2008), which are highly sodium-permeable, glutamate-gated ion channels, and expressed by these cells (Lalo et al., 2011).

While glutamate uptake and opening of ionotropic glutamate receptors seem to represent the predominant mechanisms for generating sodium signals in astrocytes, additional pathways for sodium influx are clearly present (Rose and Karus, 2013), but their contribution to activityinduced sodium signaling in astrocytes has not been investigated yet. Two interesting candidates are the $\mathrm{Na}^{+}-\mathrm{K}^{+}-2 \mathrm{Cl}^{-}$-cotransport (NKCC; (Jayakumar and Norenberg, 2010) and the electrogenic sodium-bicarbonate cotransport (NBC, (Parker and Boron, 2013). Both are stimulated by increases in extracellular potassium, albeit at different concentration levels. Direct 
activation of NKCC apparently requires relatively large increases in extracellular potassium (to more than $10 \mathrm{mM}$, (Hertz et al., 2013), indicating that sodium influx through this pathway will only be relevant during periods of strong synchronized activity. Inward NBC, in contrast, is activated by increases in the extracellular potassium in the low mM range (Pappas and Ransom, 1994), and might therefore generate measurable sodium influx into astrocytes during activityinduced increases in extracellular $\mathrm{K}^{+}$, also independent from glutamatergic signaling.

\section{3. Propagation of sodium signals in the astrocyte network}

Sodium signals are not restricted to the site of sodium influx. In hippocampal slices, locallyinduced sodium signals spread along processes of individual astrocytes at an initial velocity of $>60 \mu \mathrm{m} / \mathrm{s}$ (Langer et al., 2012), a value several times higher that of classical calcium waves (Scemes and Giaume, 2006). Furthermore, sodium signals evoked in individual cells spread in a radial manner to virtually all neighboring astrocytes within a distance of $100 \mu \mathrm{m}$. Intercellular spread of sodium in hippocampal slice preparations has been demonstrated to be primarily based on sodium diffusion through gap junctions composed of Cx30 and Cx43 ((Langer et al., 2012); Fig. 2). In addition, pharmacological inhibition of mGluR $1 / 5$ slightly dampened the spread of sodium, whereas inhibition of glutamate uptake or purinergic receptors had no effect, indicating the involvement of gliotransmission and glia-derived glutamate in the spread of sodium signals in the astrocyte network. A prominent role for gliotransmitter release has been demonstrated for the propagation of regenerative sodium waves between astrocytes in primary cell culture (Bernardinelli et al., 2004).

Thus, astrocytes possess efficient pathways for the fast redistribution of sodium in the gap-junction coupled network. This sodium diffusion through gap junctions following local synaptic activity and local sodium transients could serve to lower the metabolic load of single cells. With more extensive activity and global sodium increases in neighboring astrocytes, however, this diffusion-based pathway will no longer function effectively. Under these conditions, the generation of global calcium signals and regenerative sodium waves based on gliotransmission might together promote glucose uptake from the blood by enhancing the activity of GLUT1 at astrocyte endfeet (Barros and Deitmer, 2010). Gap junctions will then still enable diffusion of glucose from endfeet to active sites providing the fuel for increased glycolysis ((Rouach et al., 2008); Fig. 4). Accordingly, such sodium signals might not only serve to activate astrocyte metabolism, but also promote neurometabolic coupling as discussed below. 


\section{Sodium signals and neuro-metabolic coupling}

\section{1. Glutamate transport and energy metabolism}

As introduced above, maintenance of the transmembrane sodium gradient in brain cells comes with a large energy cost, estimated to account for approximately 40-60\% of brain ATP hydrolysis (Hevner et al., 1992). It is therefore expected that any cellular process involving substantial sodium movements into the cell will increase the energy load of cells, which is the case for glutamate transport. Extracellular glutamate clearance constitutes one of the most crucial roles of astrocytes in the brain, notably by continuously preventing a buildup of extracellular glutamate concentration during neuronal activity thereby avoiding excitotoxicity and enabling high frequency glutamatergic signaling. However, glutamate transport activity is also associated with substantial sodium influx into astrocytic cells (Fig. 1D, E; Fig. 2). This increased sodium influx has been proposed to constitute a pivotal element of a mechanism enabling astrocytes to increase the local availability of metabolic substrates in response to neuronal activity, through so-called "neurometabolic coupling".

In vitro studies have indicated that glutamate uptake into astrocytes cause a significant increase in their glucose uptake (Pellerin and Magistretti, 1994), which depends on the activity of the $\mathrm{Na}^{+} / \mathrm{K}^{+}$-ATPase. This observation prompted subsequent studies, which suggested that the glutamate transporter-mediated sodium influx constituted was causal to enhanced ATP consumption. It was for instance estimated from both experimental and modeling data (Chatton et al., 2000) that glutamate, applied at physiologically relevant concentrations, increases $\mathrm{Na}^{+} / \mathrm{K}^{+}$-ATPase activity by a factor of two to three. If one considers that the pump, at rest, is responsible for about half of the consumption of cellular ATP (Hevner et al., 1992) this large increase in ATP hydrolysis is bound to have important consequences on the energy budget of the cells, and the subsequent adjustment of their metabolic pathways.

It should be pointed out that other elements in addition to glutamate transporters could potentially be involved, in particular ionotropic glutamate receptors, which function as ligandgated channels for cations such as sodium, and are expressed by some astrocytes and Bergmann glia (David et al., 1996, Lalo et al., 2006, Brennan et al., 2009). Indeed, sodium signals in Bergmann glial cells in response to parallel fiber stimulation are reduced by $40 \%$ by blockers of AMPA receptors as described above (Bennay et al., 2008). Consequently, one would expect that their activation might significantly draw on the cell's energy. While this question has not yet been addressed for Bergmann glial cells, in astrocytes expressing 
relatively low levels of AMPA receptors, the rapid transition of this receptor-channel to a non-conducting inactive state following glutamate binding (Wyllie and Cull-Candy, 1994) limits the rise in intracellular sodium concentration. It follows that $\mathrm{Na}^{+} / \mathrm{K}^{+}$ATPase activity and its associated ATP hydrolysis remain close to basal levels as reported in cortical astrocytes (Chatton et al., 2000).

Enhancement of glucose capture occurs within seconds following glutamate application (Loaiza et al., 2003, Porras et al., 2008). The stimulation involves glutamate transporters and is not mimicked by AMPA receptor or metabotropic glutamate receptor activation (Porras et al., 2008). Interestingly, a co-signaling of sodium and $\mathrm{Ca}^{2+}$ was found to be required for glucose transporter stimulation (Fig. 3A), which may indicate the involvement of a signaling event such as $\mathrm{Ca}^{2+}$-dependent phosphorylation occurring on one of the kinaserecognition sites of the glucose transporter 1 (Porras et al., 2008).

Several studies have reported the existence of a physical as well as a functional association between glutamate transporters and the $\mathrm{Na}^{+} / \mathrm{K}^{+}$-ATPase $\alpha 2$ subunit (Cholet et al., 2002, Porras et al., 2008, Rose et al., 2009, Genda et al., 2011, Bauer et al., 2012, Matos et al., 2013). The physical proximity of the two elements implies that after entering the cell through the glutamate transporter, sodium can be readily handled and extruded by the $\mathrm{Na}^{+} / \mathrm{K}^{+}-\mathrm{ATPase}$. It should be kept in mind, however, that in spite of the proposed close functional interaction between glutamate transporters and the $\mathrm{Na}^{+} / \mathrm{K}^{+}$-ATPase, substantial cytosolic sodium transients are detected (see above). This shows that a substantial number of sodium ions escape the binding to, and export by, the $\mathrm{Na}^{+} / \mathrm{K}^{+}$-ATPase and diffuse from their point of entry at the membrane into the cytosol. Nonetheless, because sodium ions entering through glutamate transporters have to be expelled again by the ATP-consuming sodium pump, there should not only be a functional interaction between the two transport systems themselves, but also between glutamate transport and astrocyte energy metabolism in general.

This tight dynamic connection was further demonstrated by experiments in which intracellular sodium and ATP hydrolysis were simultaneously measured in primary astrocyte cultures (Chatton and Magistretti, 2005). Glutamate application caused a rapid intracellular sodium rise which was accompanied, without significant delay, by a sharp increase in ATP hydrolysis, the two processes occurring with the same kinetics (Fig. 3B). In the presence of glutamate, inhibition of the $\mathrm{Na}^{+} / \mathrm{K}^{+}$-ATPase using the cardiac glycoside ouabain caused the expected rapid intracellular sodium rise due to the absence of sodium efflux mechanisms, and interestingly, it also caused a concomitant large decrease in ATP hydrolysis, which reversed once the pump activity was restored (Fig. 3B). 
Apart from activity-dependent stimulation of $\mathrm{Na}^{+} / \mathrm{K}^{+}$-ATPase and glial metabolism by intracellular sodium, alternative pathways were described in neuro-metabolic coupling, involving electrogenic sodium bicarbonate cotransport (NBC; (Ruminot et al., 2011, Choi et al., 2012). It has long been known that inward NBC is activated by increases in extracellular potassium and the subsequent depolarization of astrocytes, respectively, resulting in an alkalinization of astrocytes (Deitmer and Rose, 1996, Chesler, 2003). This so-called depolarisation-induced alkalinization hasbeen shown to stimulate the phophofructokinase, and thereby activate glycolysis, bypassing the need for increases in sodium and activation of $\mathrm{Na}^{+} / \mathrm{K}^{+}$-ATPase for metabolic stimulation of astrocytes (Ruminot et al., 2011). These pathways might be especially important at for neural activity not involving glutamate.

While the neurometabolic coupling model, referred to as the "astrocyte-neuron lactate shuttle" hypothesis (Fig. 4) was initially deduced from studies using primary cultured cells, evidence that the coupling occurs in vivo and including the key role of glutamate transporters has been demonstrated as well,. In particular, quantitative autoradiographic studies using ${ }^{14} \mathrm{C}$ 2-deoxyglucose as a tracer were performed by stimulating the whisker-to-barrel pathway in anesthetized rodents while measuring local cerebral glucose utilization (Cholet et al., 2001). A significant increase in glucose utilization was seen in the activated cortical area, specifically in the barrels corresponding to the mechanically stimulated whisker. This somatotopic relationship between enhanced local neuronal activity and glucose capture and utilization disappeared when antisense GLAST oligonucleotide sequences were injected in the rat cortex (Cholet et al., 2001) and was absent in transgenic mice lacking GLAST or GLT-1 isoforms of the glutamate transporter ((Voutsinos-Porche et al., 2003); Fig. 3C). Such neurometabolic interactions were also shown to occur in vivo in brain regions other than cortex. The enhancement of intrinsic optical signal measured in the olfactory glomeruli caused by odor application was abolished by a glutamate transporter inhibition (Gurden et al., 2006). On the contrary, the intrinsic optical signals were found to be independent of postsynaptic transmission through ionotropic or metabotropic glutamate receptors. These data indicate that neuronal glutamate release and subsequent sodium-dependent uptake by astrocytes form a critical pathway through which neural activity is linked to metabolic processing.

The precise nature of the local regulation of energy metabolism is not only important for the understanding of brain function under normal physiological and pathological conditions, but also for a correct interpretation of functional brain imaging approaches, that use one or the other form of local metabolic responses to neuronal activity to generate activation maps of the brain (Figley and Stroman, 2011). In particular, the technique of ${ }^{18} \mathrm{~F}$ - 
2DG positron emission tomography (2DG-PET) yields images of brain regions with increased glucose utilization that are correlates of increased neuronal electrical activity. Therefore, the cellular localization of glucose uptake, as well as its link with electrical activity, are of prime importance. One of the important issues to clarify is whether the measured metabolic signals assumed to reflect excitatory activity, i.e. glutamate release and reuptake, and the ensuing metabolic response, also encompasses inhibitory activity. Indeed, after release from inhibitory neurons, GABA is removed from the extracellular space by sodium-dependent transporters expressed to a large extent by astrocytes (Larsson et al., 1980, Gadea and Lopez-Colome, 2001). The sodium influx associated with GABA uptake could in principle lead to the same metabolic response as glutamate. However, it has been demonstrated that the neurometabolic coupling mechanism described for glutamate cannot be directly transposed to GABA (Chatton et al., 2003), the main reason being a strikingly different kinetics of transport, rendering GABA transporters unable to sufficiently activate $\mathrm{Na}^{+} / \mathrm{K}^{+}$-ATPase.

\section{2. Sodium as an intracellular second messenger}

At the cellular level, sodium is most commonly viewed as essential for providing a driving force for transmembrane transport systems, for the generation and maintenance of membrane electrical potential, and for being a key component in the generation of fast inward currents in excitable cells. However, to some extent, it can be argued that sodium can be considered as a second messenger, a role more commonly attributed to $\mathrm{Ca}^{2+}$. This less conventional view of sodium is prompted by the analysis of the initial hypothesis of intracellular signal transduction presented by Earl Sutherland in his Nobel lecture (Sutherland, 1972). As discussed by Orlov and Hamet (2006), any intracellular molecule can be considered a potential second messenger as long as it fulfills three main criteria. (a) The modulation of the intracellular concentration of this molecule following the onset of an external stimulus precedes the cellular responses, and normalizes upon cessation of the stimulus. $(b)$ In the absence of the investigated external stimulus, the transient modulation of intracellular second messenger is per se sufficient to evoke cellular responses. (c) The interaction of second messengers with their intracellular targets is necessary for the manifestation of cellular responses.

Thus, intracellular sodium, increasing in response to glutamate stimulation, causing an increased energy demand and leading to enhanced glucose uptake and utilization, could arguably be considered an intracellular second messenger for energy metabolism. In support of this notion, the signaling role of intracellular sodium has been demonstrated in an entirely different context, namely that of the sensing of peripheral circulating sodium levels by 
neurons of the subfornical organ (SFO), one of the circumventricular organs (Shimizu et al., 2007). This specialized structure lacks a blood-brain barrier and the neurons that comprise it are exposed to the chemical environment of the peripheral circulation. Astrocytes in the SFO express the $\mathrm{Na}_{\mathrm{x}}$ channel, an atypical type of sodium channel that enables these specialized cells to act as sensors of sodium in the extracellular medium. A physiological increase of sodium level in body fluids activates a sodium signaling pathway in astrocytes, similar to that of the ANLS, triggering an enhanced glucose uptake and glycolytic response, leading to release of lactate. Lactate then increases the firing rate of local GABAergic neurons, which in turn regulate the activity of SFO efferent neurons involved in the central control of peripheral natriuremia.

Recently, the concept of sodium-glutamate transporter-mediated signaling via its associated lactate release has been extended beyond a purely energy metabolic mechanism. It was shown that lactate can spread far beyond the area of neural activity and the associated domain of glucose consumption (Cruz et al., 2007). Furthermore, released lactate has been shown to activate a class of $\mathrm{G}_{\mathrm{i}}$-protein coupled receptor, termed the hydrocarboxylic acid receptor 1 (HCAR1, formerly GPR81) first described in adipose tissue (Ahmed et al., 2009, Liu et al., 2009). HCA1 is expressed by brain cells (Bozzo et al., 2013, Lauritzen et al., 2014) and has been demonstrated to underlie a lactate-mediated negative modulation of neuronal activity (Bozzo et al., 2013). Evidence for a lactate-mediated signaling mechanism, possibly engaging another kind of receptor, was found in the locus coeruleus (Tang et al., 2014). Furthermore, lactate released as a consequence of enhanced glycogenolysis and glycolysis is also critical for long-term memory formation by inducing molecular changes, including the induction of phospho-CREB, Arc, and phospho-cofilin (Suzuki et al., 2011, Yang et al., 2014). Such lactate-mediated signaling between glial cells and neurons may constitute a signal for a multicellular metabolic recruitment (Barros, 2013) or for providing a metabolic feedback on neuronal activity (Bozzo et al., 2013, Tang et al., 2014).

\section{3. Mitochondrial sodium and energy metabolism}

When considering the role of intracellular sodium in cellular energy metabolism, it should be kept in mind that the main powerhouses of cells are the mitochondria that host the tricarboxylic acid cycle and are the site of the oxidative phosphorylation. Whereas the glycolysis discussed above yields only two ATP molecules per glucose consumed, oxidative phosphorylation produces seventeen-fold more ATP per glucose molecule. In astrocytes, glutamate transporters co-compartmentalize with the $\mathrm{Na}^{+} / \mathrm{K}^{+}$-ATPase, as well as with 
glycolytic enzymes and mitochondria (Genda et al., 2011, Bauer et al., 2012). In addition, it has been demonstrated that movements of mitochondria stabilize at sites of glutamate uptake (Jackson et al., 2014). This raises the question of the functional purpose of this proximity of mitochondria with the major membrane sodium influx pathway.

Energized mitochondria generate and maintain a large electrical gradient -of typically of $-180 \mathrm{mV}$ - across their inner membrane. As a consequence, cations such as sodium should have a strong tendency to be taken up into the mitochondrial matrix. However, it has been long thought that mitochondria possess a very low permeability for monovalent cations, a property enabling them to generate the large proton motive force necessary for oxidative phosphorylation (Bernardi, 1999). Nevertheless, measurements of intramitochondrial sodium performed inside living astrocytes have revealed that cytosolic sodium changes are faithfully transmitted to the mitochondrial matrix (Fig. 3D) (Bernardinelli et al., 2006). Despite the large electronegativity of mitochondria, the resting intramitochondrial sodium levels are maintained only slightly higher $(\sim 19 \mathrm{mM})$ than in the cytosol mainly by the activity of the mitochondrial $\mathrm{Na}^{+} / \mathrm{H}^{+}$exchanger (Pozzo-Miller et al., 1997, Bernardi, 1999, Bernardinelli et al., 2006). The consequence of the mitochondrial sodium influx following cellular glutamate uptake is not obvious. A likely action is through the ensuing acidification of mitochondria, which reduces mitochondrial respiration, therefore contributing to the glycolytic metabolic response (Azarias et al., 2011, Perreten Lambert et al., 2014).

The roles of mitochondrial sodium influx may extend beyond the glutamate-evoked responses discussed above. Indeed, it was observed, that single mitochondria in astrocytes display spontaneous sodium spiking activity (Azarias et al., 2008) that coincide with rapid mitochondrial transients of $\mathrm{pH}$ and reactive oxygen species, possibly related to the availability of ATP in the mitochondrial microdomain (Azarias et al., 2011). Similar single mitochondrial spiking events were found in a variety of cell types and organisms, including plants (Schwarzlander et al., 2012) and C. elegans (Shen et al., 2014). However, the mechanistic nature and function of these events is still debated (Schwarzlander et al., 2012, Schwarzlander et al., 2014). Mitochondrial spiking activity is increasingly thought to represent a novel frequency-coded readout of metabolism at the single mitochondria level (Schwarzlander et al., 2014).

While mitochondria do not appear to accumulate sodium, their ability to take up and release sodium ions may enable them to influence the kinetics of local sodium fluctuations as proposed for $\mathrm{Ca}^{2+}$ in neuronal presynaptic boutons (Scotti et al., 1998). Other subcellular compartments may be relevant for cellular sodium regulation, such as the endoplasmic 
reticulum, a major $\mathrm{Ca}^{2+}$ store critically involved in the fast release and reuptake of $\mathrm{Ca}^{2+}$ ions during agonist-evoked responses or calcium-induced calcium release. While experimentally difficult to address, quantitative X-ray microanalysis studies of cryosections of hippocampal slices estimated that ER sodium levels in dendrites are somewhat higher than in the cytoplasm ( $\sim 19 \mathrm{mM})$ and can substantially increase during trains of action potentials (Pozzo-Miller et al., 1997).

\section{Consequences of sodium homeostasis disturbances in the diseased brain}

Disturbance of the cellular sodium handling is highly likely to impact the functional integrity of neurons and other brain cells and hence may plausibly play a causal role in the generation of pathophysiological neurological or psychiatric conditions. Conversely, altered sodium homeostasis is known to result from pathological brain conditions, in particular during cerebral ischemia. These situations may be connected to specific sodium-dependent membrane transporters or linked with intracellular homeostasis. Several plasma membrane transport systems, such as the sodium-glutamate transporters or those involved in brain $\mathrm{pH}$ regulation $\left(\mathrm{Na}^{+} / \mathrm{H}^{+}\right.$exchangers and $\mathrm{Na}^{+} / \mathrm{HCO}_{3}{ }^{-}$cotransporters), critically depend on the integrity of brain sodium homeostasis. Other sodium-dependent transporters stand out for their involvement in certain brain pathologies.

The $\mathrm{Na}^{+} / \mathrm{Ca}^{2+}$ exchanger (NCX) that contributes to a large extent to the establishment of the large inwardly directed $\mathrm{Ca}^{2+}$ gradient, is expressed by both neurons and glia (Annunziato et al., 2013). When intracellular sodium rises to abnormal concentrations, the transporter reverses its mode of operation and drives the entry of $\mathrm{Ca}^{2+}$ from the extracellular milieu. This so-called reversal mode of NCX (Philipson and Nicoll, 2000) may have several deleterious consequences for brain cells. In particular, excessive intracellular $\mathrm{Ca}^{2+}$ rise leads to mitochondrial dysfunction (Putney et al., 2002) or further glutamate release by glia (Paluzzi et al., 2007), which in turn contributes to the worsening of pathological conditions such as those found in ischemic insults. The $\mathrm{Na}^{+} / \mathrm{K}^{+} / 2 \mathrm{Cl}^{-}$co-transporters (NKCC) are expressed in neurons, where they regulate the intracellular $\mathrm{Cl}^{-}$concentration and therefore neuronal excitability. In astrocytes, this transporter plays an important role in the control of extracellular $\mathrm{K}^{+}$concentration as well as cell volume regulation (Kofuji and Newman, 2004, Jayakumar and Norenberg, 2010). As introduced above, stimulation of NKCC1 activity such as that occurring during ischemia, may lead to the loss of sodium homeostasis with the consequence of increasing cytoplasmic $\mathrm{Ca}^{2+}$ following stimulation of NCX reverse mode 
activation (Lenart et al., 2004). Aberrant activation of NKCC1 is also believed to cause deleterious astrocyte swelling during epileptic activity (Hochman, 2012).

Finally, the most important regulator of sodium homeostasis, the $\mathrm{Na}^{+} / \mathrm{K}^{+}$-ATPase, is critically susceptible to ATP depletion, such as that which occurs during ischemic stroke or severe hypoglycemia, which ultimately leads to the loss of the sodium and $\mathrm{K}^{+}$transmembrane gradients in these conditions. $\mathrm{Na}^{+} / \mathrm{K}^{+}$-ATPase gene mutations have also been linked to familial hemiplegic migraine (Capendeguy and Horisberger, 2004). Impaired $\mathrm{Na}^{+} / \mathrm{K}^{+}$ATPase activity is inevitably accompanied by the failure of transporters discussed above (NCX, NKCC, etc.) that are critical for the proper brain function at the cellular and network level. 


\section{Acknowledgements}

Work in the authors' laboratories is supported by grants from the Deutsche Forschungsgemeinschaft to CRR (DFG: Ro2327/8-1) and the Swiss National Science Foundation (SNF) to JYC. We thank Jennifer I. Luebke for her critical reading of the manuscript. 


\section{References}

Ahmed K, Tunaru S, Offermanns S (2009) GPR109A, GPR109B and GPR81, a family of hydroxy-carboxylic acid receptors. Trends Pharmacol Sci 30:557-562.

Ames A, 3rd (2000) CNS energy metabolism as related to function. Brain Res Brain Res Rev 34:42-68.

Anderson CM, Swanson RA (2000) Astrocyte glutamate transport: review of properties, regulation, and physiological functions. Glia 32:1-14.

Annunziato L, Boscia F, Pignataro G (2013) Ionic transporter activity in astrocytes, microglia, and oligodendrocytes during brain ischemia. J Cereb Blood Flow Metab 33:969-982.

Azarias G, Kruusmagi M, Connor S, Akkuratov EE, Liu XL, Lyons D, Brismar H, Broberger C, Aperia A (2013) A specific and essential role for Na,K-ATPase alpha3 in neurons co-expressing alpha1 and alpha3. J Biol Chem 288:2734-2743.

Azarias G, Perreten H, Lengacher S, Poburko D, Demaurex N, Magistretti PJ, Chatton J-Y (2011) Glutamate transport decreases mitochondrial $\mathrm{pH}$ and modulates oxidative metabolism in astrocytes. Journal of Neuroscience 31:3550-3559.

Azarias G, Van De Ville D, Unser M, Chatton J-Y (2008) Spontaneous $\mathrm{Na}^{+}$transients in individual mitochondria of intact astrocytes. Glia 56:342-353.

Baranauskas G, David Y, Fleidervish IA (2013) Spatial mismatch between the Na+ flux and spike initiation in axon initial segment. Proc Natl Acad Sci U S A 110:4051-4056.

Barros LF (2013) Metabolic signaling by lactate in the brain. Trends Neurosci.

Barros LF, Deitmer JW (2010) Glucose and lactate supply to the synapse. Brain Res Rev 63:149-159.

Bauer DE, Jackson JG, Genda EN, Montoya MM, Yudkoff M, Robinson MB (2012) The glutamate transporter, GLAST, participates in a macromolecular complex that supports glutamate metabolism. Neurochem Int 61:566-574.

Bennay M, Langer J, Meier SD, Kafitz KW, Rose CR (2008) Sodium signals in cerebellar Purkinje neurons and Bergmann glial cells evoked by glutamatergic synaptic transmission. Glia 56:1138-1149.

Bergles DE, Diamond JS, Jahr CE (1999) Clearance of glutamate inside the synapse and beyond. Curr Opin Neurobiol 9:293-298.

Bernardi P (1999) Mitochondrial transport of cations: channels, exchangers, and permeability transition. Physiol Rev 79:1127-1155. 
Bernardinelli Y, Azarias G, Chatton JY (2006) In situ fluorescence imaging of glutamateevoked mitochondrial $\mathrm{Na}+$ responses in astrocytes. Glia 54:460-470.

Bernardinelli Y, Chatton JY (2008) Differential effects of glutamate transporter inhibitors on the global electrophysiological response of astrocytes to neuronal stimulation. Brain Res 1240:47-53.

Bernardinelli Y, Magistretti PJ, Chatton JY (2004) Astrocytes generate Na+-mediated metabolic waves. Proc Natl Acad Sci U S A 101:14937-14942.

Bittner CX, Valdebenito R, Ruminot I, Loaiza A, Larenas V, Sotelo-Hitschfeld T, Moldenhauer H, San Martin A, Gutierrez R, Zambrano M, Barros LF (2011) Fast and reversible stimulation of astrocytic glycolysis by $\mathrm{K}+$ and a delayed and persistent effect of glutamate. J Neurosci 31:4709-4713.

Blanco G, Mercer RW (1998) Isozymes of the Na-K-ATPase: heterogeneity in structure, diversity in function. Am J Physiol 275:F633-650.

Bowman CL, Kimelberg HK (1984) Excitatory amino acids directly depolarize rat brain astrocytes in primary culture. Nature 311:656-659.

Bozzo L, Chatton JY (2010) Inhibitory effects of (2S, 3S)-3-[3-[4(trifluoromethyl)benzoylamino]benzyloxy]aspartate (TFB-TBOA) on the astrocytic sodium responses to glutamate. Brain Res 1316:27-34.

Bozzo L, Puyal J, Chatton JY (2013) Lactate modulates the activity of primary cortical neurons through a receptor-mediated pathway. PLoS One 8:e71721.

Brennan AM, Suh SW, Won SJ, Narasimhan P, Kauppinen TM, Lee H, Edling Y, Chan PH, Swanson RA (2009) NADPH oxidase is the primary source of superoxide induced by NMDA receptor activation. Nat Neurosci 12:857-863.

Callaway JC, Ross WN (1997) Spatial distribution of synaptically activated sodium concentration changes in cerebellar Purkinje neurons. J Neurophysiol 77:145-152.

Capendeguy O, Horisberger J-D (2004) Functional effects of Na+,K+-ATPase gene mutations linked to familial hemiplegic migraine. Neuromolecular medicine 6:105-116.

Chatton J-Y, Magistretti PJ (2005) Relationship between L-glutamate-regulated intracellular $\mathrm{Na}^{+}$dynamics and ATP hydrolysis in astrocytes. Journal of Neural Transmission 112:77-85.

Chatton JY, Marquet P, Magistretti PJ (2000) A quantitative analysis of L-glutamateregulated $\mathrm{Na}^{+}$dynamics in mouse cortical astrocytes: implications for cellular bioenergetics. Eur J Neurosci 12:3843-3853. 
Chatton JY, Pellerin L, Magistretti PJ (2003) GABA uptake into astrocytes is not associated with significant metabolic cost: implications for brain imaging of inhibitory transmission. Proc Natl Acad Sci U S A 100:12456-12461.

Chatton JY, Shimamoto K, Magistretti PJ (2001) Effects of glial glutamate transporter inhibitors on intracellular $\mathrm{Na}+$ in mouse astrocytes. Brain Res 893:46-52.

Chesler M (2003) Regulation and modulation of pH in the brain. Physiol Rev 83:1183-1221.

Choi HB, Gordon GR, Zhou N, Tai C, Rungta RL, Martinez J, Milner TA, Ryu JK, McLarnon JG, Tresguerres M, Levin LR, Buck J, Macvicar BA (2012) Metabolic Communication between Astrocytes and Neurons via Bicarbonate-Responsive Soluble Adenylyl Cyclase. Neuron 75:1094-1104.

Cholet N, Pellerin L, Magistretti PJ, Hamel E (2002) Similar perisynaptic glial localization for the $\mathrm{Na}+\mathrm{K}+-\mathrm{ATPase}$ alpha 2 subunit and the glutamate transporters GLAST and GLT-1 in the rat somatosensory cortex. Cereb Cortex 12:515-525.

Cholet N, Pellerin L, Welker E, Lacombe P, Seylaz J, Magistretti P, Bonvento G (2001) Local injection of antisense oligonucleotides targeted to the glial glutamate transporter GLAST decreases the metabolic response to somatosensory activation. J Cereb Blood Flow Metab 21:404-412.

Crambert G, Geering K (2003) FXYD proteins: new tissue-specific regulators of the ubiquitous Na,K-ATPase. Sci STKE 2003:RE1.

Cruz NF, Ball KK, Dienel GA (2007) Functional imaging of focal brain activation in conscious rats: impact of $[(14) C]$ glucose metabolite spreading and release. J Neurosci Res 85:3254-3266.

Danbolt NC (2001) Glutamate uptake. Prog Neurobiol 65:1-105.

David JC, Yamada KA, Bagwe MR, Goldberg MP (1996) AMPA receptor activation is rapidly toxic to cortical astrocytes when desensitization is blocked. Journal of Neuroscience 16:200-209.

Deitmer JW, Rose CR (1996) $\mathrm{pH}$ regulation and proton signalling by glial cells. Prog Neurobiol 48:73-103.

Deitmer JW, Rose CR (2010) Ion changes and signalling in perisynaptic glia. Brain Res Rev 63:113-129.

Dietzel I, Heinemann U, Hofmeier G, Lux HD (1982) Stimulus-induced changes in extracellular $\mathrm{Na}+$ and $\mathrm{Cl}$ - concentration in relation to changes in the size of the extracellular space. Exp Brain Res 46:73-84. 
Erecinska M, Silver IA (1994) Ions and energy in mammalian brain. Prog Neurobiol 43:3771.

Figley CR, Stroman PW (2011) The role(s) of astrocytes and astrocyte activity in neurometabolism, neurovascular coupling, and the production of functional neuroimaging signals. Eur J Neurosci 33:577-588.

Fleidervish IA, Lasser-Ross N, Gutnick MJ, Ross WN (2010) Na+ imaging reveals little difference in action potential-evoked $\mathrm{Na}+$ influx between axon and soma. Nat Neurosci 13:852-860.

Gadea A, Lopez-Colome AM (2001) Glial transporters for glutamate, glycine, and GABA: II. GABA transporters. J Neurosci Res 63:461-468.

Gegelashvili G, Schousboe A (1998) Cellular distribution and kinetic properties of highaffinity glutamate transporters. Brain Res Bull 45:233-238.

Genda EN, Jackson JG, Sheldon AL, Locke SF, Greco TM, O'Donnell JC, Spruce LA, Xiao R, Guo W, Putt M, Seeholzer S, Ischiropoulos H, Robinson MB (2011) Cocompartmentalization of the astroglial glutamate transporter, GLT-1, with glycolytic enzymes and mitochondria. J Neurosci 31:18275-18288.

Gurden H, Uchida N, Mainen ZF (2006) Sensory-evoked intrinsic optical signals in the olfactory bulb are coupled to glutamate release and uptake. Neuron 52:335-345.

Hablitz JJ, Heinemann U (1989) Alterations in the microenvironment during spreading depression associated with epileptiform activity in the immature neocortex. Brain Res Dev Brain Res 46:243-252.

Harris JJ, Jolivet R, Attwell D (2012) Synaptic energy use and supply. Neuron 75:762-777.

Hertz L, Xu J, Song D, Yan E, Gu L, Peng L (2013) Astrocytic and neuronal accumulation of elevated extracellular $\mathrm{K}(+)$ with a $2 / 3 \mathrm{~K}(+) / \mathrm{Na}(+)$ flux ratio-consequences for energy metabolism, osmolarity and higher brain function. Front Comput Neurosci 7:114.

Hevner RF, Duff RS, Wong-Riley MT (1992) Coordination of ATP production and consumption in brain: parallel regulation of cytochrome oxidase and $\mathrm{Na}+\mathrm{K}(+)-$ ATPase. Neurosci Lett 138:188-192.

Hochman D (2012) The extracellular space and epileptic activity in the adult brain: explaining the antiepileptic effects of furosemide and bumetanide. Epilepsia 53 Suppl 1:18-25.

Hodgkin A, Huxley A (1952) A quantitative description of membrane current and its application to conduction and excitation in nerve. J Physiol 117:500-544.

Howarth C, Gleeson P, Attwell D (2012) Updated energy budgets for neural computation in the neocortex and cerebellum. J Cereb Blood Flow Metab 32:1222-1232. 
Jackson JG, O'Donnell JC, Takano H, Coulter DA, Robinson MB (2014) Neuronal activity and glutamate uptake decrease mitochondrial mobility in astrocytes and position mitochondria near glutamate transporters. J Neurosci 34:1613-1624.

Jaffe DB, Johnston D, Lasser-Ross N, Lisman JE, Miyakawa H, Ross WN (1992) The spread of $\mathrm{Na}+$ spikes determines the pattern of dendritic $\mathrm{Ca} 2+$ entry into hippocampal neurons. Nature 357:244-246.

Jayakumar AR, Norenberg MD (2010) The Na-K-Cl Co-transporter in astrocyte swelling. Metab Brain Dis 25:31-38.

Kala G, Kumarathasan R, Peng L, Leenen FH, Hertz L (2000) Stimulation of Na+,K+ATPase activity, increase in potassium uptake, and enhanced production of ouabainlike compounds in ammonia-treated mouse astrocytes. Neurochem Int 36:203-211.

Kanai R, Ogawa H, Vilsen B, Cornelius F, Toyoshima C (2013) Crystal structure of a Na+bound $\mathrm{Na}+\mathrm{K}+-\mathrm{ATPase}$ preceding the E1P state. Nature 502:201-206.

Kaplan JH (2002) Biochemistry of Na,K-ATPase. Annu Rev Biochem 71:511-535.

Kettenmann H, Backus KH, Schachner M (1984) Aspartate, glutamate and gammaaminobutyric acid depolarize cultured astrocytes. Neurosci Lett 52:25-29.

Kimelberg HK, Pang S, Treble DH (1989) Excitatory amino acid-stimulated uptake of 22Na+ in primary astrocyte cultures. J Neurosci 9:1141-1149.

Kirischuk S, Kettenmann H, Verkhratsky A (2007) Membrane currents and cytoplasmic sodium transients generated by glutamate transport in Bergmann glial cells. Pflugers Arch 454:Kirischuk et al., Pflügers Arch; 245-252.

Kirischuk S, Parpura V, Verkhratsky A (2012) Sodium dynamics: another key to astroglial excitability? Trends Neurosci 35:497-506.

Kofuji P, Newman EA (2004) Potassium buffering in the central nervous system. Neuroscience 129:1045-1056.

Kohr G, Heinemann U (1989) Effects of NMDA antagonists on picrotoxin-, low Mg2+- and low $\mathrm{Ca} 2+-$ induced epileptogenesis and on evoked changes in extracellular $\mathrm{Na}+$ and Ca2+ concentrations in rat hippocampal slices. Epilepsy Res 4:187-200.

Kole MH, Ilschner SU, Kampa BM, Williams SR, Ruben PC, Stuart GJ (2008) Action potential generation requires a high sodium channel density in the axon initial segment. Nat Neurosci 11:178-186.

Kushmerick MJ, Podolsky RJ (1969) Ionic mobility in muscle cells. Science 166:1297-1298. 
Lalo U, Pankratov Y, Kirchhoff F, North RA, Verkhratsky A (2006) NMDA receptors mediate neuron-to-glia signaling in mouse cortical astrocytes. J Neurosci 26:26732683.

Lalo U, Pankratov Y, Parpura V, Verkhratsky A (2011) Ionotropic receptors in neuronalastroglial signalling: what is the role of "excitable" molecules in non-excitable cells. Biochim Biophys Acta 1813:992-1002.

Lamy CM, Chatton JY (2011) Optical probing of sodium dynamics in neurons and astrocytes. Neuroimage 58:572-578.

Langer J, Rose CR (2009) Synaptically induced sodium signals in hippocampal astrocytes in situ. J Physiol 587:5859-5877.

Langer J, Stephan J, Theis M, Rose CR (2012) Gap junctions mediate intercellular spread of sodium between hippocampal astrocytes in situ. Glia 60:239-252.

Larsson OM, Hertz L, Schousboe A (1980) GABA uptake in astrocytes in primary cultures: coupling with two sodium ions. Journal of Neuroscience Research 5:469-477.

Lasser-Ross N, Ross WN (1992) Imaging voltage and synaptically activated sodium transients in cerebellar Purkinje cells. Proc Biol Sci 247:35-39.

Lauritzen KH, Morland C, Puchades M, Holm-Hansen S, Hagelin EM, Lauritzen F, Attramadal H, Storm-Mathisen J, Gjedde A, Bergersen LH (2014) Lactate receptor sites link neurotransmission, neurovascular coupling, and brain energy metabolism. Cereb Cortex 24:2784-2795.

Lenart B, Kintner DB, Shull GE, Sun D (2004) Na-K-Cl cotransporter-mediated intracellular na+ accumulation affects $\mathrm{Ca} 2+$ signaling in astrocytes in an in vitro ischemic model. $\mathrm{J}$ Neurosci 24:9585-9597.

Lennie P (2003) The cost of cortical computation. Curr Biol 13:493-497.

Liu C, Wu J, Zhu J, Kuei C, Yu J, Shelton J, Sutton SW, Li X, Yun SJ, Mirzadegan T, Mazur C, Kamme F, Lovenberg TW (2009) Lactate inhibits lipolysis in fat cells through activation of an orphan G-protein-coupled receptor, GPR81. J Biol Chem 284:28112822.

Loaiza A, Porras OH, Barros LF (2003) Glutamate triggers rapid glucose transport stimulation in astrocytes as evidenced by real-time confocal microscopy. J Neurosci 23:7337-7342.

Maragakis NJ, Rothstein JD (2004) Glutamate transporters: animal models to neurologic disease. Neurobiol Dis 15:461-473. 
Marcaggi P, Attwell D (2004) Role of glial amino acid transporters in synaptic transmission and brain energetics. Glia 47:217-225.

Matos M, Augusto E, Agostinho P, Cunha RA, Chen JF (2013) Antagonistic Interaction between Adenosine A2A Receptors and Na+/K+-ATPase-alpha2 Controlling Glutamate Uptake in Astrocytes. J Neurosci 33:18492-18502.

Morth JP, Pedersen BP, Buch-Pedersen MJ, Andersen JP, Vilsen B, Palmgren MG, Nissen P (2011) A structural overview of the plasma membrane $\mathrm{Na}+\mathrm{K}+-\mathrm{ATPa} e$ and $\mathrm{H}+-$ ATPase ion pumps. Nat Rev Mol Cell Biol 12:60-70.

Nedergaard M (1994) Direct signaling from astrocytes to neurons in cultures of mammalian brain cells. Science 263:1768-1771.

Nuriya M, Yasui M (2013) Endfeet serve as diffusion-limited subcellular compartments in astrocytes. J Neurosci 33:3692-3698.

Nyblom M, Poulsen H, Gourdon P, Reinhard L, Andersson M, Lindahl E, Fedosova N, Nissen P (2013) Crystal structure of $\mathrm{Na}+, \mathrm{K}(+)$-ATPase in the $\mathrm{Na}(+)$-bound state. Science 342:123-127.

Orlov SN, Hamet P (2006) Intracellular monovalent ions as second messengers. J Membr Biol 210:161-172.

Paluzzi S, Alloisio S, Zappettini S, Milanese M, Raiteri L, Nobile M, Bonanno G (2007) Adult astroglia is competent for $\mathrm{Na}+/ \mathrm{Ca} 2+$ exchanger-operated exocytotic glutamate release triggered by mild depolarization. J Neurochem 103:1196-1207.

Pappas CA, Ransom BR (1994) Depolarization-induced alkalinization (DIA) in rat hippocampal astrocytes. J Neurophysiol 72:2816-2826.

Parker MD, Boron WF (2013) The divergence, actions, roles, and relatives of sodium-coupled bicarbonate transporters. Physiol Rev 93:803-959.

Pellerin L, Magistretti PJ (1994) Glutamate uptake into astrocytes stimulates aerobic glycolysis: a mechanism coupling neuronal activity to glucose utilization. Proc Natl Acad Sci U S A 91:10625-10629.

Pellerin L, Magistretti PJ (1997) Glutamate uptake stimulates Na+,K+-ATPase activity in astrocytes via activation of a distinct subunit highly sensitive to ouabain. J Neurochem 69:2132-2137.

Perreten Lambert H, Zenger M, Azarias G, Chatton JY, Magistretti PJ, Lengacher S (2014) Control of Mitochondrial $\mathrm{pH}$ by Uncoupling Protein 4 in Astrocytes Promotes Neuronal Survival. J Biol Chem. 
Philipson KD, Nicoll DA (2000) Sodium-calcium exchange: a molecular perspective. Annu Rev Physiol 62:111-133.

Porras OH, Ruminot I, Loaiza A, Barros LF (2008) $\mathrm{Na}^{+}-\mathrm{Ca}^{2+}$ cosignaling in the stimulation of the glucose transporter GLUT1 in cultured astrocytes. Glia 56:59-68.

Pozzo-Miller LD, Pivovarova NB, Leapman RD, Buchanan RA, Reese TS, Andrews SB (1997) Activity-dependent calcium sequestration in dendrites of hippocampal neurons in brain slices. J Neurosci 17:8729-8738.

Putney LK, Denker SP, Barber DL (2002) The changing face of the Na+/H+ exchanger, NHE1: structure, regulation, and cellular actions. Annu Rev Pharmacol Toxicol 42:527-552.

Rose CR, Karus C (2013) Two sides of the same coin: sodium homeostasis and signaling in astrocytes under physiological and pathophysiological conditions. Glia 61:1191-1205.

Rose CR, Konnerth A (2001) NMDA receptor-mediated Na+ signals in spines and dendrites. J Neurosci 21:4207-4214.

Rose CR, Kovalchuk Y, Eilers J, Konnerth A (1999) Two-photon Na+ imaging in spines and fine dendrites of central neurons. Pflugers Arch 439:201-207.

Rose CR, Ransom BR (1996a) Intracellular sodium homeostasis in rat hippocampal astrocytes. J Physiol 491 ( Pt 2):291-305.

Rose CR, Ransom BR (1996b) Mechanisms of $\mathrm{H}^{+}$and $\mathrm{Na}^{+}$changes induced by glutamate, kainate, and D-Aspartate in rat hippocampal astrocytes. J Neurosci 16:5393-5404.

Rose CR, Ransom BR (1997a) Gap junctions equalize intracellular Na+ concentration in astrocytes. Glia 20:299-307.

Rose CR, Ransom BR (1997b) Regulation of intracellular sodium in cultured rat hippocampal neurones. J Physiol 499 ( Pt 3):573-587.

Rose EM, Koo JC, Antflick JE, Ahmed SM, Angers S, Hampson DR (2009) Glutamate transporter coupling to Na,K-ATPase. J Neurosci 29:8143-8155.

Rouach N, Koulakoff A, Abudara V, Willecke K, Giaume C (2008) Astroglial metabolic networks sustain hippocampal synaptic transmission. Science 322:1551-1555.

Ruminot I, Gutierrez R, Pena-Munzenmayer G, Anazco C, Sotelo-Hitschfeld T, Lerchundi R, Niemeyer MI, Shull GE, Barros LF (2011) NBCe1 mediates the acute stimulation of astrocytic glycolysis by extracellular K+. J Neurosci 31:14264-14271.

Scemes E, Giaume C (2006) Astrocyte calcium waves: what they are and what they do. Glia 54:716-725. 
Schousboe A, Sarup A, Bak LK, Waagepetersen HS, Larsson OM (2004) Role of astrocytic transport processes in glutamatergic and GABAergic neurotransmission. Neurochem Int 45:521-527.

Schreiner AE, Durry S, Aida T, Stock MC, Ruther U, Tanaka K, Rose CR, Kafitz KW (2014) Laminar and subcellular heterogeneity of GLAST and GLT-1 immunoreactivity in the developing postnatal mouse hippocampus. J Comp Neurol 522:204-224.

Schwarzlander M, Logan DC, Johnston IG, Jones NS, Meyer AJ, Fricker MD, Sweetlove LJ (2012) Pulsing of membrane potential in individual mitochondria: a stress-induced mechanism to regulate respiratory bioenergetics in Arabidopsis. Plant Cell 24:11881201.

Schwarzlander M, Wagner S, Ermakova YG, Belousov VV, Radi R, Beckman JS, Buettner GR, Demaurex N, Duchen MR, Forman HJ, Fricker MD, Gems D, Halestrap AP, Halliwell B, Jakob U, Johnston IG, Jones NS, Logan DC, Morgan B, Muller FL, Nicholls DG, Remington SJ, Schumacker PT, Winterbourn CC, Sweetlove LJ, Meyer AJ, Dick TP, Murphy MP (2014) The 'mitoflash' probe cpYFP does not respond to superoxide. Nature 514:E12-14.

Scotti AL, Chatton J-Y, Reuter H (1998) Roles of $\mathrm{Na}^{+} / \mathrm{Ca}^{2+}$ exchange and of mitochondria in the regulation of presynaptic $\mathrm{Ca}^{2+}$ and spontaneous glutamate release. Phil Trans $\mathrm{R}$ Soc Lond B 354:357-364.

Sheldon C, Cheng YM, Church J (2004) Concurrent measurements of the free cytosolic concentrations of $\mathrm{H}(+)$ and $\mathrm{Na}(+)$ ions with fluorescent indicators. Pflugers Arch 449:307-318.

Shen EZ, Song CQ, Lin Y, Zhang WH, Su PF, Liu WY, Zhang P, Xu J, Lin N, Zhan C, Wang X, Shyr Y, Cheng H, Dong MQ (2014) Mitoflash frequency in early adulthood predicts lifespan in Caenorhabditis elegans. Nature 508:128-132.

Shimizu H, Watanabe E, Hiyama TY, Nagakura A, Fujikawa A, Okado H, Yanagawa Y, Obata K, Noda M (2007) Glial Nax channels control lactate signaling to neurons for brain $[\mathrm{Na}+]$ sensing. Neuron 54:59-72.

Skou JC, Esmann M (1992) The Na,K-ATPase. J Bioenerg Biomembr 24:249-261.

Somjen GG (2004) Ions in the brain: Normal function, seizures, and stroke: Oxford University Press, New York.

Sutherland EW (1972) Studies on the mechanism of hormone action. Science 177:401-408. 
Suzuki A, Stern SA, Bozdagi O, Huntley GW, Walker RH, Magistretti PJ, Alberini CM (2011) Astrocyte-neuron lactate transport is required for long-term memory formation. Cell 144:810-823.

Sykova E, Nicholson C (2008) Diffusion in brain extracellular space. Physiol Rev 88:12771340.

Tang F, Lane S, Korsak A, Paton JF, Gourine AV, Kasparov S, Teschemacher AG (2014) Lactate-mediated glia-neuronal signalling in the mammalian brain. Nat Commun $5: 3284$.

Tsukada S, Iino M, Takayasu Y, Shimamoto K, Ozawa S (2005) Effects of a novel glutamate transporter blocker, (2S, 3S)-3-[3-[4-(trifluoromethyl)benzoylamino]benzyloxy] aspartate (TFB-TBOA), on activities of hippocampal neurons. Neuropharmacology 48:479-491.

Tzingounis AV, Wadiche JI (2007) Glutamate transporters: confining runaway excitation by shaping synaptic transmission. Nat Rev Neurosci 8:935-947.

Unichenko P, Dvorzhak A, Kirischuk S (2013) Transporter-mediated replacement of extracellular glutamate for GABA in the developing murine neocortex. Eur J Neurosci 38:3580-3588.

Unichenko P, Myakhar O, Kirischuk S (2012) Intracellular Na(+) concentration influences short-term plasticity of glutamate transporter-mediated currents in neocortical astrocytes. Glia 60:605-614.

Uwechue NM, Marx MC, Chevy Q, Billups B (2012) Activation of glutamate transport evokes rapid glutamine release from perisynaptic astrocytes. J Physiol 590:2317-2331.

Voutsinos-Porche B, Bonvento G, Tanaka K, Steiner P, Welker E, Chatton JY, Magistretti PJ, Pellerin L (2003) Glial glutamate transporters mediate a functional metabolic crosstalk between neurons and astrocytes in the mouse developing cortex. Neuron 37:275-286.

Wyllie DJ, Cull-Candy SG (1994) A comparison of non-NMDA receptor channels in type-2 astrocytes and granule cells from rat cerebellum. J Physiol 475:95-114.

Yang J, Ruchti E, Petit JM, Jourdain P, Grenningloh G, Allaman I, Magistretti PJ (2014) Lactate promotes plasticity gene expression by potentiating NMDA signaling in neurons. Proc Natl Acad Sci U S A 111:12228-12233.

Zahler R, Zhang ZT, Manor M, Boron WF (1997) Sodium kinetics of Na,K-ATPase alpha isoforms in intact transfected HeLa cells. J Gen Physiol 110:201-213. 
Zanotto L, Heinemann U (1983) Aspartate and glutamate induced reductions in extracellular free calcium and sodium concentration in area CA1 of 'in vitro' hippocampal slices of rats. Neurosci Lett 35:79-84. 


\section{Figure Captions}

Fig. 1. Activity-induced sodium signals. (A) extracellular sodium signals in the sensorimotor cortex (depth $600 \mu \mathrm{m}$ ) of cats induced by electrical stimulation of the cortical surface with 20 $\mathrm{Hz}, 0.2 \mathrm{~ms}$ for $10 \mathrm{~s}$. (B), (C) sodium signals in neurons. (B) Left: 3D reconstruction of a layer 2/3 pyramidal neuron patched with ANG-containing electrolyte. Scale bar, $30 \mu \mathrm{m}$. Right: Dendritic fluorescence transients recorded during backpropagation of action potentials (top). Space over time display of the matching linescan recording (bottom). (C) Top left: Image of a spiny dendrite of a CA1 pyramidal cell. Closed arrowheads indicate "active" and open arrowheads "passive" spines from which measurements were taken; scale bar: $5 \mu \mathrm{m}$. Top right: Suprathreshold stimulation ( 5 pulses at $50 \mathrm{~Hz}$ ) induced 5 APs as measured at the soma. Upper traces: Average activity-induced sodium transient in spines (average of 19) and in the dendrite. Middle traces: sodium transients in 3 single "passive" spines. Lower traces: sodium transients in 3 single "active" spines. (D), (E) sodium signals in astrocytes. (D) Top: Fluorescence image of astrocytes in a cortical slice double-stained with sulforhodamine 101 (left panel) and ANG (center panel). Scale bar, $30 \mu \mathrm{m}$. Magnification of an ANG stained astrocyte (right panel). Scale bar, $5 \mu \mathrm{m}$. Bottom: Sample trace of astrocytic fluorescence response to glutamate puffs of increasing durations. (E) inward current and sodium transients in different processes of a Bergmann glial cell during parallel fibers stimulation $(50 \mathrm{~Hz}, 100$ $\mathrm{ms})$. Signals were largest in processes that were located close to the stimulation pipette. Taken from: (A) Dietzel et. al. (1982), (B) Lamy \& Chatton 2011, (C) Rose et al. 2001, (D) Lamy \& Chatton 2011, (E) Bennay et al. 2008.

Fig. 2. Pathways for sodium influx at glutamatergic synapses. At glutamatergic synapses, action-potentials induce sodium influx into neurons through TTX-sensitive voltage-gated sodium channels. If dendrites carry back-propagating action-potentials, these mediate sodium influx through voltage-gated channels, too. At the postsynaptic site, ionotropic glutamate receptor channels (NMDA and AMPA) represent major sodium influx pathways into dendrites and spines. At the same time, activation of high-affinity, sodium-dependent glutamate transporters results in sodium uptake into astrocytes, resulting in sodium signals in these cells, which can spread to neighboring astrocytes through gap junctions.

Fig. 3: Sodium signals and astrocyte metabolism. (A) Upper traces: calcium (filled symbols) and sodium (open symbols) signals in astrocytes in culture, induced by application of 
endothelin-1 and/or gramicidin during the periods indicated. The lower traces show that only coincidence of both signals causes stimulation of glucose transport (as monitored by uptake of 6-NBDG). (B) Interrelationship between intracellular magnesium concentration (determined by fluorescence imaging with MagnesiumGreen) and sodium (determined by imaging with SBFI). Whereas application of glutamate causes an increase in both sodium and magnesium (the latter indicating a reduction in ATP content), inhibition of the sodium pump by ouabain causes a further rise in sodium, but a decrease in free magnesium, indicative of a recovery of intracellular ATP levels. (C) Enhancement of glucose utilization and lactate formation induced by glutamate application depend on the expression of glutamate transporters. Glucose utilization, evaluated by intracellular accumulation of 2-Deoxyglucose (top), and lactate release (bottom) under control conditions and after application of glutamate (Glu) in cortical astrocytes in culture derived from wildtype (+/+), heterozygous (+/-), and GLAST mutant mice (-/-). (D) Sodium signals in mitochondria. Glutamate induces an increase in cytosolic sodium (determined by $\mathrm{SBFI}$ ) as well as intramitochondrial sodium (determined by CoroNaRed) in cultured astrocytes. Diazoxide, a $\mathrm{K}_{\mathrm{ATP}}$ channel opener caused an increase in mirochondrial sodium only. Taken from: (A), Porras et al (2008); (B), Magistretti \& Chatton (2005); (C), Voutsinos-Porche et al. (2003); (D), Bernardinelli et al (2006).

Fig. 4: Major pathways involved in neuro-metabolic coupling between astrocytes and neurons. At glutamatergic synapses, activation of glutamate transport generates sodium signals in astrocytes which are also transmitted to mitochondria. Cytosolic sodium increases cause activation of $\mathrm{Na}^{+} / \mathrm{K}^{+}$-ATPase, which results in increased consumption of ATP. In addition, protons entering cells during glutamate transport activity are transmitted to mitochondria where they weaken the respiratory chain. The enhanced ATP consumption by astrocytes is followed by increased uptake of glucose from the blood. Lactate dehydrogenase (LDH) converts the resulting pyruvate to lactate which is then shuttled from astrocytes to active neurons, where it serves as metabolite substrate for ATP production after its conversion to pyruvate by the LDH. In addition, release of $\mathrm{K}^{+}$by active neurons into the extracellular space, causes astrocyte membrane depolarization and influx of bicarbonate through $\mathrm{Na}^{+}-$ bicarbonate cotransporters. The resulting glial alkalinization further stimulates glycolytic enzymes toward the production and release of lactate. 
A stimulus-induced sodium changes in the ECS

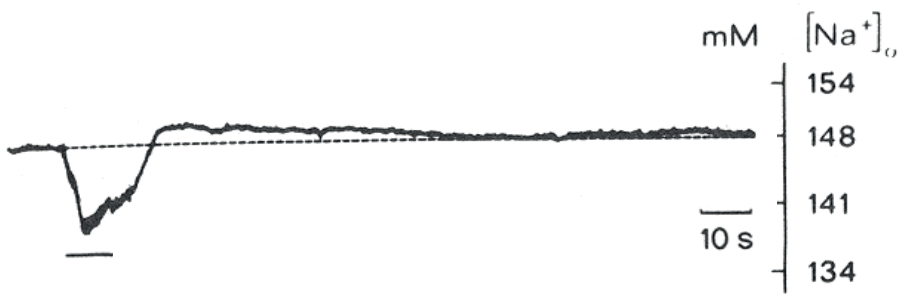

B AP-induced sodium changes

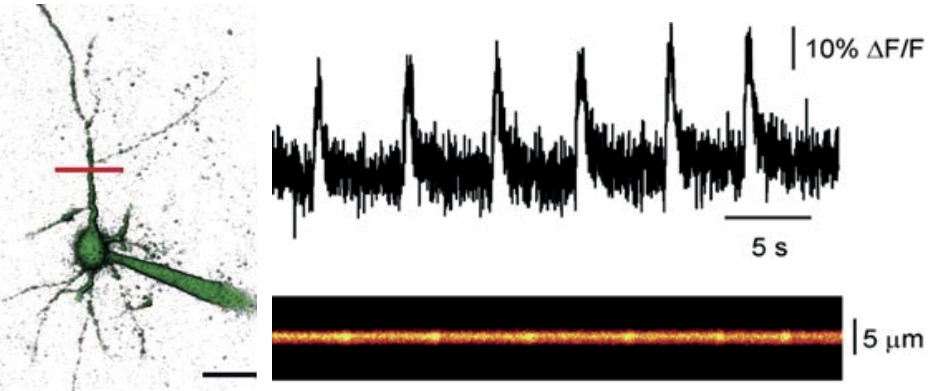

D cortical astrocytes
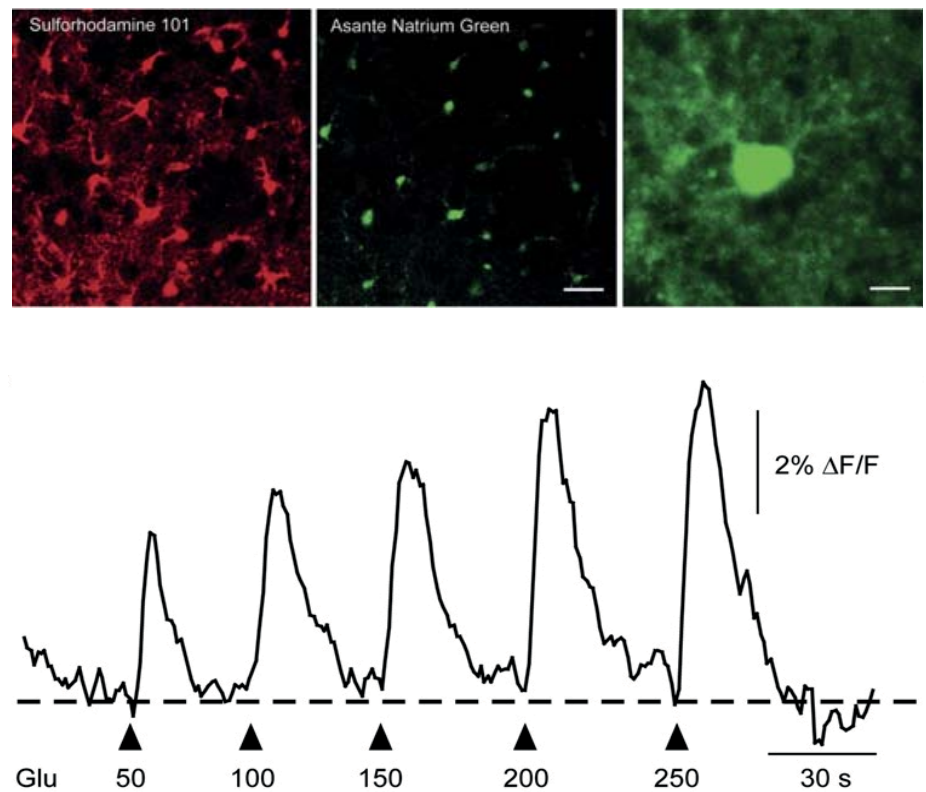

C sodium changes in spines and dendrites
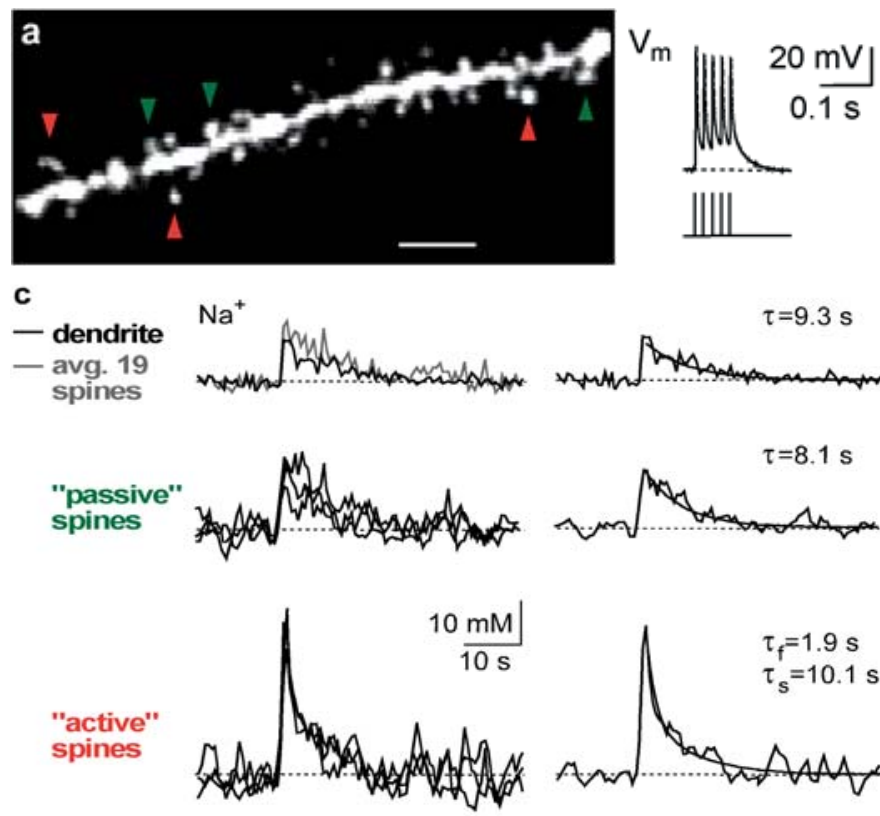

$\Delta$

$\Delta$

E Bergmann glial cell
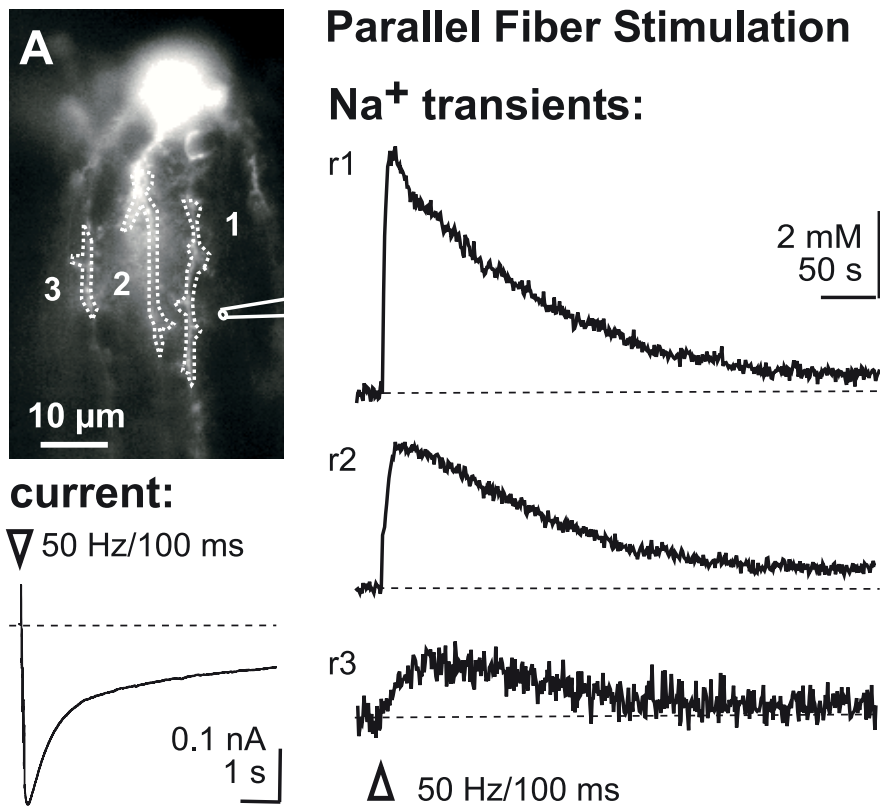

$\Delta 50 \mathrm{~Hz} / 100 \mathrm{~ms}$

Fig. 1: Rose \& Chatton 


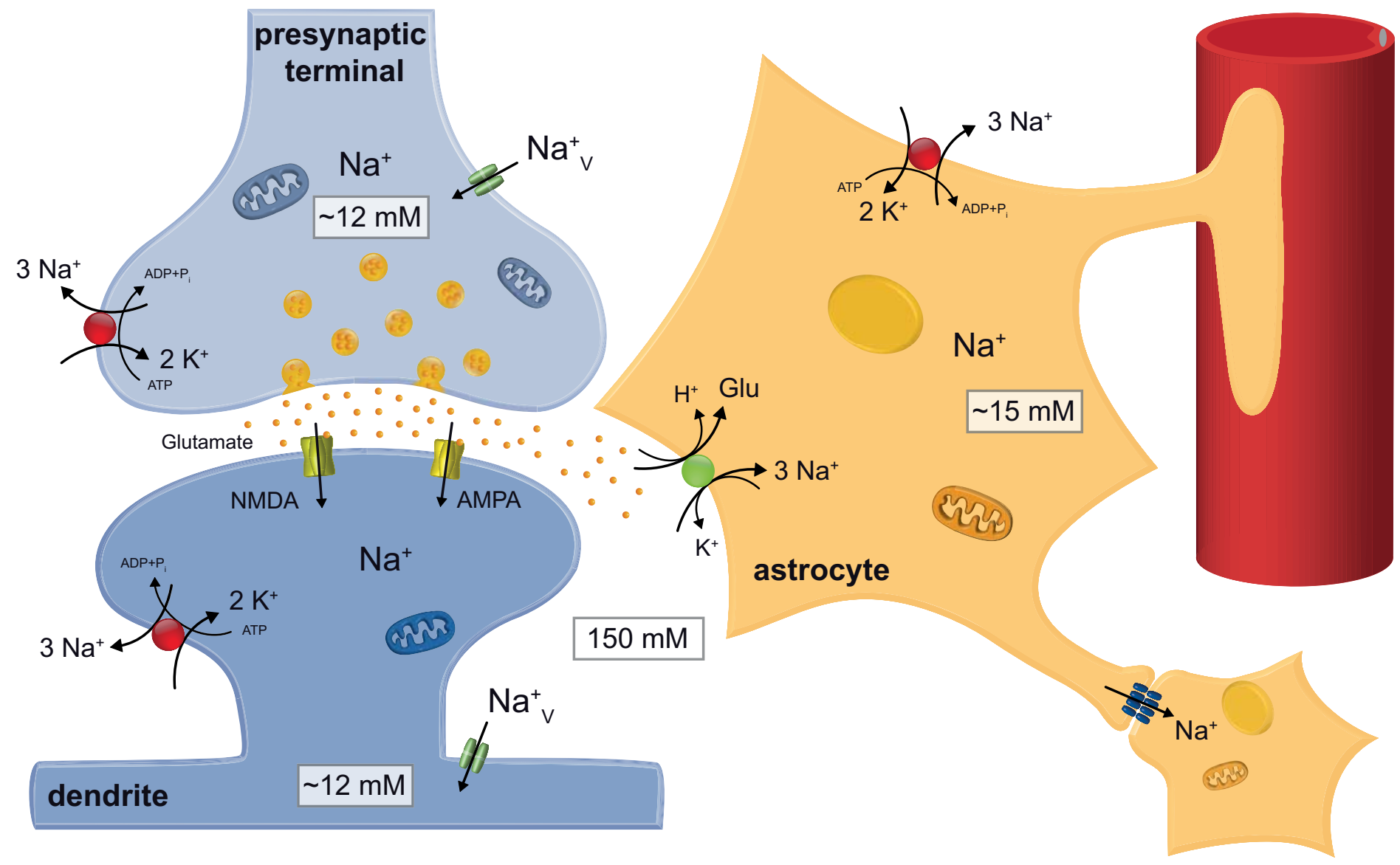

Fig. 2: Rose \& Chatton 
A GLUT1 stimulation by coincidental sodium and calcium signals
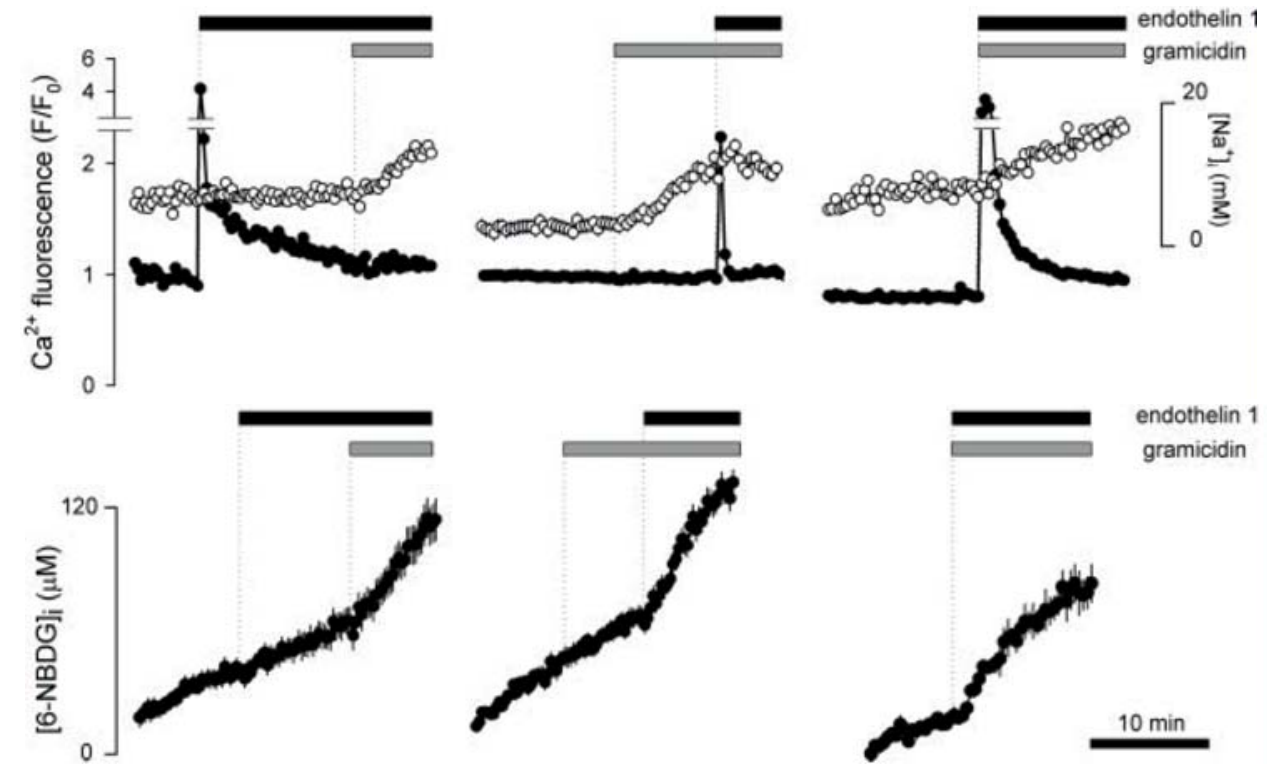

C glucose utilization and lactate formation in GLAST mutant mice

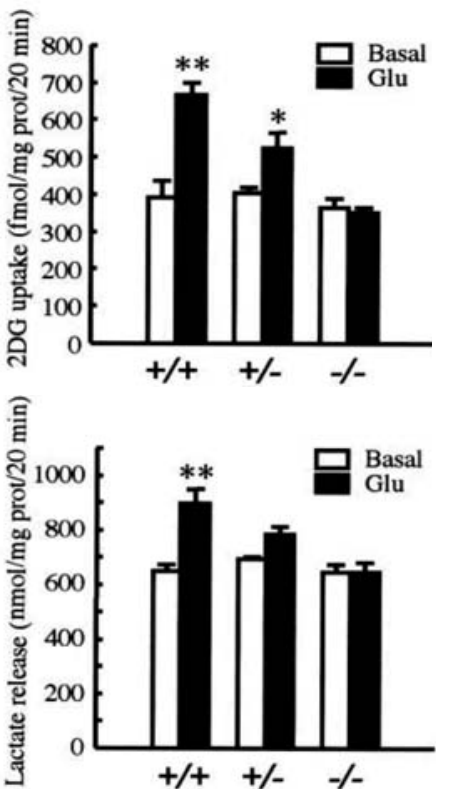

B correlation between changes in intracellular free

D sodium entry into mitochondria

magnesium and sodium

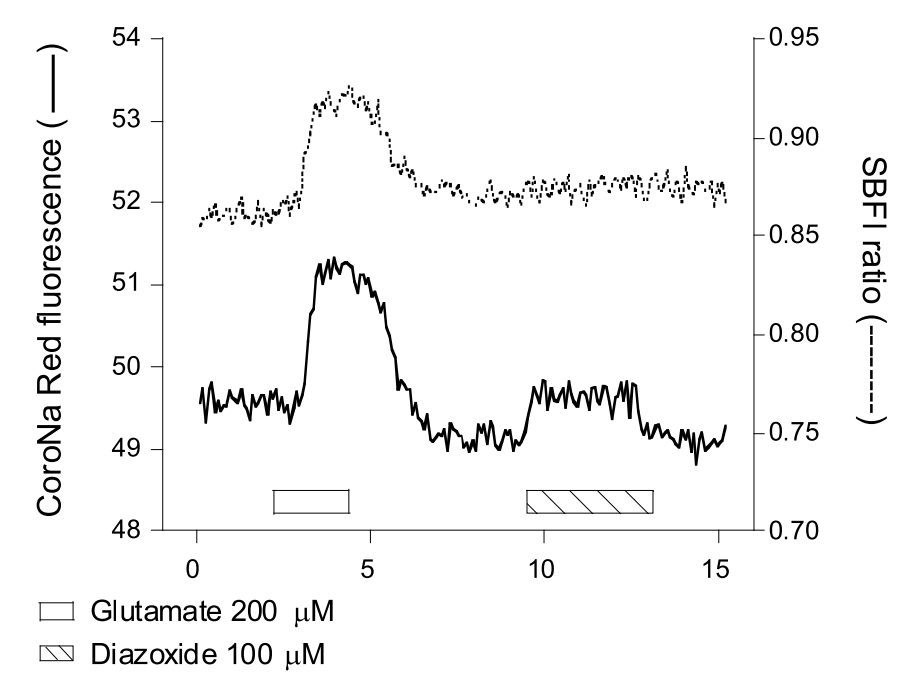

Fig. 3: Rose \& Chatton 


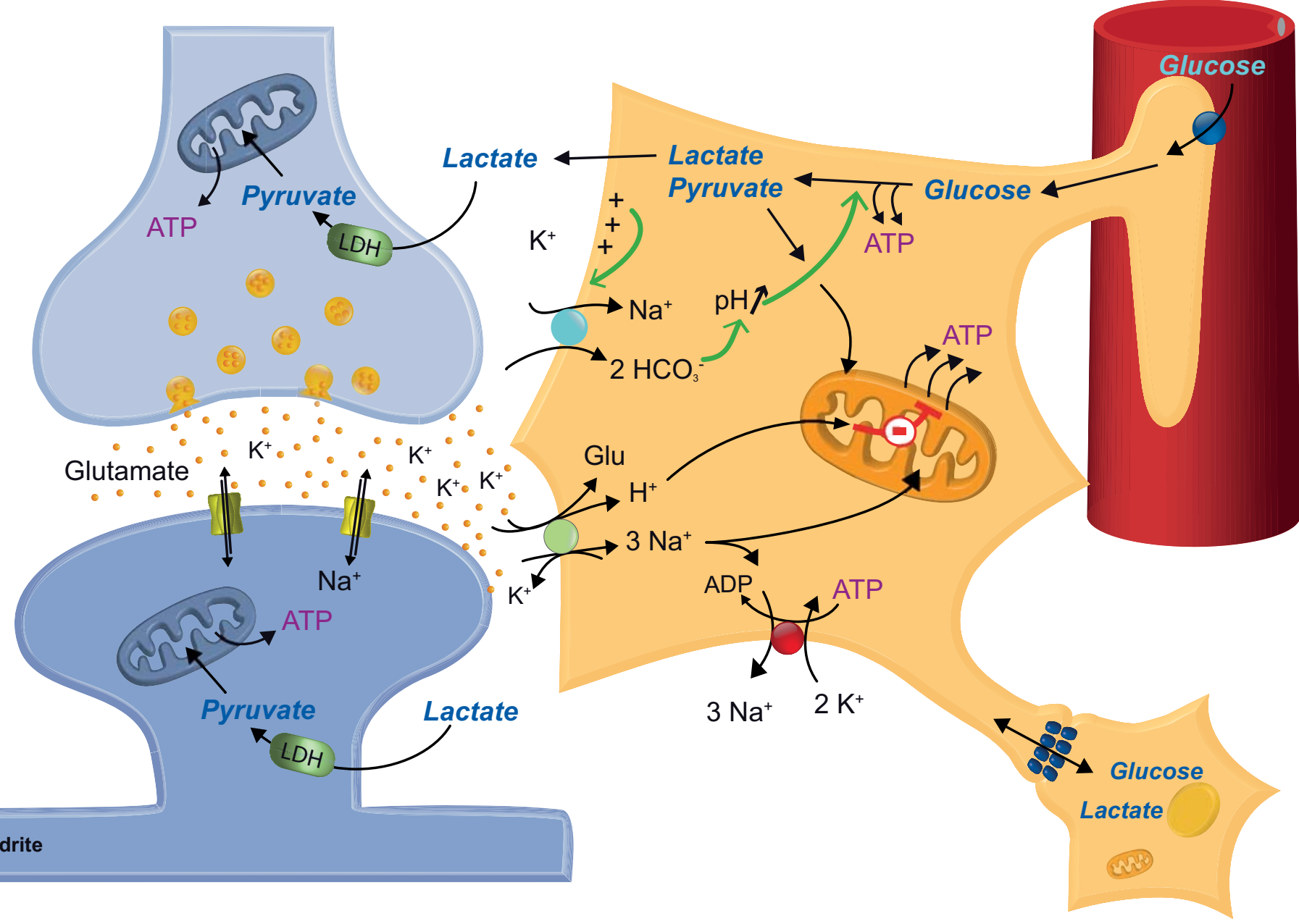

Fig. 4: Rose \& Chatton 


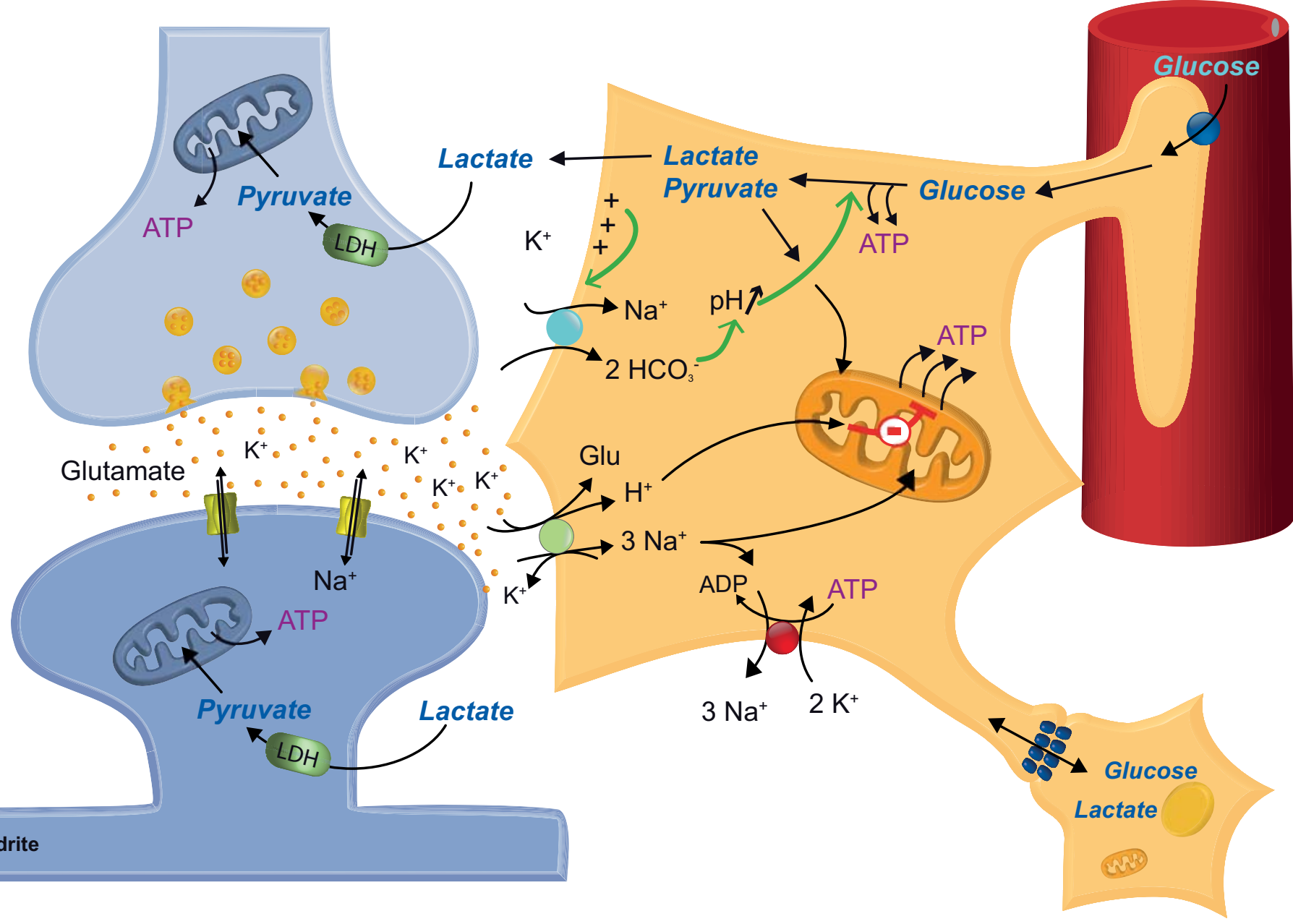

